NBER WORKING PAPER SERIES

\title{
WHAT DO AGGREGATE CONSUMPTION \\ EULER EQUATIONS SAY ABOUT \\ THE CAPITAL INCOME TAX BURDEN?
}

\author{
Casey B. Mulligan \\ Working Paper 10262 \\ http://www.nber.org/papers/w10262
NATIONAL BUREAU OF ECONOMIC RESEARCH 1050 Massachusetts Avenue
Cambridge, MA 02138
January 2004

I appreciate the thoughtful comments of Antonio Rangel. This research was made possible by financial support from the University of Chicago's George Stigler Center for the Study of the Economy and the State, and joint work with Jason Hwang and Justin Marion. The views expressed herein are those of the authors and not necessarily those of the National Bureau of Economic Research.

(C2004 by Casey B. Mulligan. All rights reserved. Short sections of text, not to exceed two paragraphs, may be quoted without explicit permission provided that full credit, including (C) notice, is given to the source. 
What do Aggregate Consumption Euler Equations Say about the Capital Income Tax Burden? Casey B. Mulligan

NBER Working Paper No. 10262

January 2004

JEL No. E21, H30, E22

\section{$\underline{\text { ABSTRACT }}$}

Aggregate consumption Euler equations fit financial asset return data poorly. But they fit the return on the capital stock well, which leads us to three empirical findings relating to the capital income tax burden. First, capital taxation drives a wedge between consumption growth and the expected pretax capital return. Second, capital taxation is the major distortion in the capital market, in the sense that most of the medium and long run deviations between expected consumption growth and the expected pre-tax capital return are associated with capital taxation. Third, consumption growth appears to be pretty elastic to the after-tax capital return (i.e., capital is elastically supplied), even while it appears inelastic to returns on various financial assets. Capital income taxes are passed on through reduced capital accumulation, or higher markups, or some combination.

Casey B. Mulligan

University of Chicago

Department of Economics

1126 East 59th Street, \#506

Chicago, IL 60637

and NBER

c-mulligan@uchicago.edu 


\section{Introduction}

Capital income taxes are important because they produce revenue for the Treasury, and may have significant effects on capital accumulation and the distribution of after-tax income. Although the consumption Euler equation is about some of the intertemporal choice associated with capital accumulation, and has been the subject of many empirical investigations, the aggregate consumption Euler equation literature might seem a poor source of information on the burden of capital income taxes. After all, public finance theory seems to speak about the behavior of individual households and firms, whereas aggregate measures of behavior may be complicated functions of heterogeneity and many dimensions of individual behavior. In practice, aggregate consumption Euler equations fit poorly, and rarely include measures of capital taxation (eg., Hansen and Singleton 1983).

But the complicated nature of aggregate behavior, and the poor fit of empirical Euler equations are precisely the reasons why aggregate consumption Euler equations are so informative. First of all, some of the questions of primary interest in public finance such as tax policy consequences for aggregate deadweight costs and the amount of revenue received by the Treasury, are questions about aggregates. These aggregates are determined by behaviors on a number of different margins, and it can be informative to look at aggregates directly. ${ }^{1}$ For example, even if a careful microeconometric study showed us that firms use capital and labor in fixed proportions, we should not conclude that capital is inelastically demanded, because capital may adjust via the shut down of capital intensive operations.

Second, and maybe more important, the poor fit of consumption Euler equations tells us that financial asset prices are determined mainly by factors unrelated to the supply of and demand for capital. Even if the data showed that, say, bond interest rates were uncorrelated with rates of consumption growth, or uncorrelated with rates of capital accumulation, we cannot easily draw conclusions about the supply and demand for capital because bond rates could be very weakly

${ }^{1}$ Feldstein (1995) is one important step in this direction, considering the variety of responses to individual income taxation as summarized by taxable income. 
correlated with returns to capital owners, or costs of capital users.

With these features in mind, this paper uses aggregate consumption Euler equations to describe the capital income tax burden, and obtains three empirical results using U.S. data. First, capital taxation drives a wedge between consumption growth and the expected pre-tax capital return. Second, capital taxation is the major distortion in the capital market, in the sense that most of the medium and long run deviations between expected consumption growth and the expected pre-tax capital return are associated with capital taxation. Third, consumption growth appears to be pretty elastic to the after-tax capital return, even while it appears inelastic to returns on various financial assets.

\section{The Tax Wedge from the Euler Equation Perspective}

Consider a capital income tax levied on consumers at rate $\tau_{t}$ on their capital income in year $t$. Let $r_{t}^{i}$ denote the pre-tax return on asset $i$ between years $t-1$ and $t$, net of principal and depreciation. In order to focus on the potential lessons from Euler equation analysis, let's suppose that asset $i$ 's "capital income" for tax purposes is $r_{t}^{i}$ per dollar of capital in place in year $t$ - 1 , so that the after-tax return net of principal is $\left(1-\tau_{t}\right) r_{t}^{i}$. Obviously we are not modeling the tax system in its full reality, because we implicitly assume that the capital income tax base includes real rather than nominal interest, deducts real economic depreciation, includes real capital gains upon accrual, etc., although adjustments of the tax rate might help bring the model a little closer to reality in these dimensions.

One margin of substitution for the representative consumer is therefore to forego one unit of consumption in year $t-1$ in return for $\left[1+\left(1-\tau_{t}\right) r_{t}^{i}\right]$ units in year $t$. The return, and perhaps even the tax rate, may be uncertain, so the first order condition equates "in expectation" the intertemporal marginal rate of substitution (hereafter, IMRS) to the gross return $\left[1+\left(1-\tau_{t}\right) r_{t}^{i}\right]$. More precisely, when

using the familiar power consumption growth formula for the IMRS, we have a consumption Euler equation for any asset $i$ : 


$$
E_{t-1}\left[\frac{1+\left(1-\tau_{t}\right) r_{t}^{i}}{e^{\rho}\left(c_{t} / c_{t-1}\right)^{1 / \sigma}}\right]=1
$$

where $c_{t}$ is consumption in year $t . \sigma$ is often interpreted as the intertemporal elasticity of substitution, and $\rho$ as the rate of time preference.

Empirical failures of the Euler equation (1) are seen in a variety of ways. For example, the equation suggests that expected consumption growth should be correlated with expected after-tax asset returns (either because high expected returns encourage delayed consumption, or because investors demand high returns when they are delaying their consumption), but these correlations are hard to find when the assets in question are any of the familiar financial assets, like Treasury Bills, or the S\&P 500 (Hall 1988). Or equation (1) can be differenced for asset $i$ and asset $j$, implying that asset $i$ has a greater expected return than asset $j$ to the extent that asset $i$ 's return has the higher covariance with consumption growth. While it seems easy to find empirical examples of assets with different expected returns (e.g., stocks versus bonds), it is hard to attribute the excess expected returns to consumption risk (Mehra and Prescott 1985).

It is important to extend asset pricing theory beyond the Euler equation (1), but Mulligan (2004) argues that many such extensions (both existing and still undeveloped) can be summarized according to the Euler equation (1)'

$$
E_{t-1}\left[\frac{1+\left(1-\tau_{t}\right) r_{t}^{i}}{e^{\rho}\left(c_{t} / c_{t-1}\right)^{1 / \sigma}}\right]=\alpha_{t-1}^{i}
$$

where $\alpha$ generally varies over time and across assets. The $\alpha$ 's may be interpreted as subjective probability adjustments (Harrison and Kreps 1979, Cagetti et al 2002), reflections of asset-specific clientele (Alvarez and Jermann 2001), liquidity services, other financial market frictions, etc., but Mulligan (2004) emphasizes two (empirically refutable) implications that are common to many interpretations. First, $\alpha$ is one for the capital stock, so the capital stock is well priced with 
consumption alone (equivalently, capital's expected return is a good predictor of consumption growth). Second, assets in small net aggregate supply - including Treasury Bills and even the S\&P 500 - have their prices determined by additional factors, embodied in the $\alpha$ 's, independent from average consumption. One reason for these results is that assets in small net aggregate supply have special clientele, whereas the average consumer (whose consumption appears in the Euler equation) is holding the average asset - something like the capital stock.

Since $\alpha=1$ for the capital stock, equations (1) and (1)' are a particular form of the familiar public finance proposition that (anticipated) capital income taxes drive a wedge between the pre-tax capital return $r^{k}$ (which, under familiar conditions, is the marginal product of capital) and the IMRS. Conversely, this theory says that any wedge between $r^{k}$ and the IMRS is entirely attributed to capital income taxation. In order to focus on the tax wedge, it is useful to rearrange equation (1) in order to separate the public and private behaviors, as in equation $(1)^{\prime \prime}:^{2}$

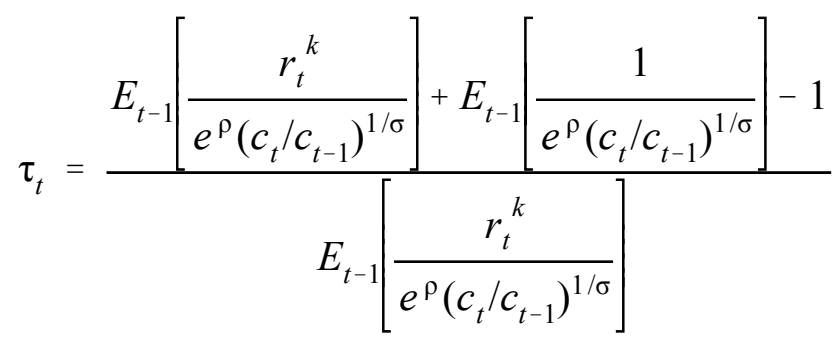

The LHS of (1)" is the capital income tax rate, determined by the government, and the RHS is the wedge between the pre-tax capital return $r^{k}$ and IMRS, determined by savers, investors, and technology. LHS is not only supposed to be positively correlated with RHS, but the two are supposed to fluctuate in equal amounts - fundamental implications of this theory which need not be confirmed by the data. ${ }^{3}$

The theory works well at medium and low frequencies. Figure 1 displays 5-year moving averages of three time series, 1947-97. The first (solid) is a measure of the LHS of (1)", namely

${ }^{2}$ For simplicity we use the assumption that capital income tax rates are known at least one year ahead.

${ }^{3}$ For example, alternative theories might assume that capital taxes are unanticipated, or that government regulations offset the distortionary effects of taxation, etc. 
capital income tax revenue per dollar of capital income. ${ }^{4}$ The other two are measures of the wedge between $r^{k}$ and IMRS, calculated by assuming a particular value for $\sigma$ (2.5 for the dashed series, as suggested by Mulligan's 2002 estimates; 1.13 for the dash-dot, as suggested by Table 1 below), measuring $r^{k}$ as pre-tax capital income per dollar of capital, measuring $c$ as real nondurable and services consumption expenditures per person age $15+$, calculating expectations as fitted values from VARs, and calibrating $\rho$ so that the resulting time series had the same average level as the measured tax rates.

4“"Capital income tax revenue" includes revenues from federal, state, and local corporate income, property, and (a portion of) personal income taxes. Capital income is from the National Income and Product Accounts. This measure follows statutory tax rates pretty closely; see Mulligan (2003a) for more details. 


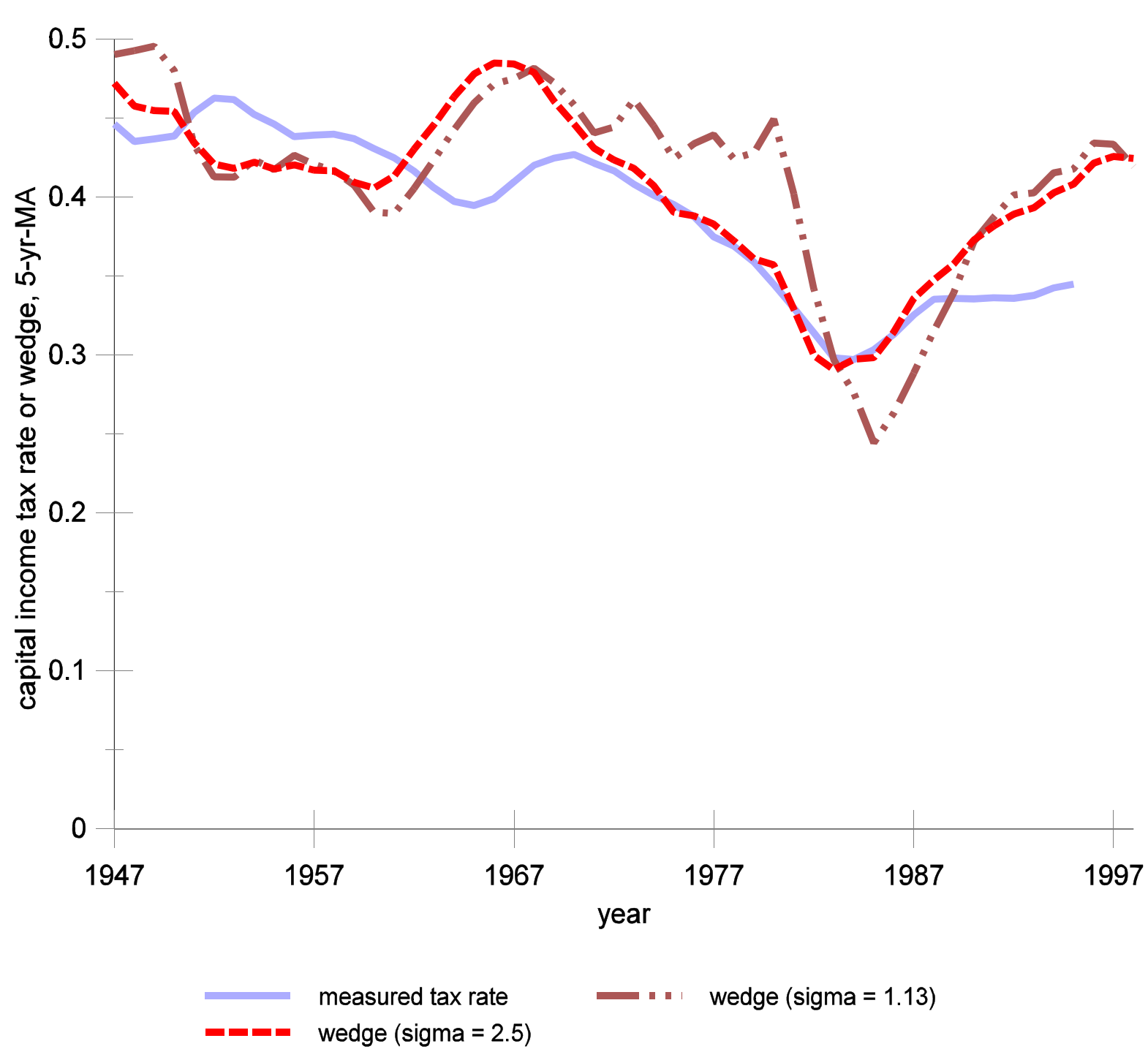

Figure 1 Capital Income Taxation has Driven a Wedge between $r^{k}$ and IMRS

Prior to the Kennedy tax cut, the wedge is fairly constant (i.e., consumption growth roughly followed the expected pre-tax capital return), very much like the measured tax rate. The Kennedy tax cut does not seem to fit the theory, because pre-tax return and consumption growth moved apart rather than moving together. Since then, the three time series are similar - all declining about 13 percentage points 1970-83, and all increasing since 1983, although the wedges increase more since 1988. All series move in a range with similar breadth - all have a maximum about 15-20 percentage points above their minimum.

Results would be very different if we had used the return on a financial asset like commercial paper or the S\&P 500, rather than the capital stock, because the consumption Euler equation fits 
financial asset returns much worse. For example, while the annual time series standard deviation of the LHS of equation (1) - calculated using the same measures and similar VARS as in the construction of Figure 1 - is only 0.006 for the capital return, it is 0.025 for the commercial paper return, and 0.076 for the S\&P 500 return (Mulligan 2004). At best, financial asset returns are noisy indicators of capital income tax wedges. At worst, some of the asset pricing puzzles (the $\alpha$ 's in our notation) respond to tax policy, so that financial asset returns could systematically overstate or understate capital income tax wedges, and the financial asset Euler equations would systematically bias estimates of tax policy consequences.

\section{The Elasticity of Capital Supply}

The elasticity of capital supply is a critical parameter for forecasting the economic incidence and impacts of capital income tax policies, and even some labor tax policies, such as those "phased in" over time (Auerbach and Kotlikoff 1987, p. 50). The consumption Euler equation literature tells us a lot about estimating that parameter. Namely, because the consumption Euler equations fit financial asset returns so poorly, the elasticity is likely to be underestimated by one or two orders of magnitude by the elasticity of consumption growth with respect to a financial asset return.

Table 1 reports estimates of the elasticity of consumption growth with respect to an expected asset return, using 51 postwar annual observations. The specifications differ according to the asset for which the return is measured. The first row is a regression of consumption growth on the real commercial paper return (namely, the nominal yield promised in year $t-1$ minus inflation between $t-1$ and $t$ ), instrumenting using the lagged real commercial paper return, and other lagged variables. The regression coefficient is usually interpreted as an elasticity with respect to the expected return, because the fitted value from the first stage is something like an expected return. As Hall (1988) found for a similar regression, the return coefficient is economically insignificant. Results are similar when we exchange the commercial paper return for another financial asset return, such as the S \& P 500 return used in the second row. Results are dramatically different if capital's after-tax return is used, as shown in the last specification. The elasticity of consumption growth with respect 
to the return is greater than one, with a $95 \%$ confidence interval of 0.6 to $1.7 .^{5}$

Table 1: Asset Returns and Consumption Growth, 1947-97

\begin{tabular}{lccc} 
asset & elasticity with respect to expected return & adj-R ${ }^{2}$ & DW-stat \\
\hline commercial paper & 0.14 & .07 & 1.43 \\
& $(0.07)$ & & \\
S \& P 500 & 0.09 & .00 & 1.59 \\
& $(0.02)$ & & \\
BEA capital & 1.13 & .23 & 1.57 \\
& $(0.29)$ & & \\
\hline
\end{tabular}

Notes: (1) Each row in the table is a TSLS regression.

(2) Dependent variable is $\ln \left(c_{t} / c_{t-1}\right)$, with $c_{t}$ as year $t$ nondurables and services expenditure per capita. coefficient standard errors in parenthesis. constant terms are estimated, but not reported in the table.

(3) First stage regression is actual return on lagged return, lagged nominal commercial paper yield (promised for maturity in year $t$ ), lagged BAA minus AAA promised bond yield, lagged inflation rate.

(4) BEA capital return is after-tax. Mulligan $(2002,2004)$ reports more details

\section{Capital Income Tax Incidence}

Over the $20^{\text {th }}$ Century in the U.S., there is a clear negative correlation between the log of the pre-tax capital return $r_{t}^{k}$ and the log of the after-capital-income-tax share $\left(1-\tau_{t}\right)$ (Krzyzaniak and Musgrave 1963, updated by Feldstein et al 1983 and Mulligan 2003). The simplest, but possibly naive, interpretation of this correlation is that firms respond to capital taxation by raising prices and or moving up their capital demand curve, thereby passing on the capital income tax. Economists have long hesitated to adopt this simple interpretation, because capital tax rates seem correlated with non-tax determinants of economic activity. For example, tax rates were high during WWII and low during the Great Depression, and we doubt that tax policy alone was responsible for the high and low pre-tax capital returns, respectively.

${ }^{5}$ The Durbin-Watson statistic of 1.57 is less than two, although the Cochrane-Orcutt estimate of the error term first order serial correlation coefficient is insignificantly different from zero. It may also seem that the large elasticity shown in the Table's $3^{\text {rd }}$ row could also be explained by savings "rules of thumb", but Mulligan (2002 pp. 35-6, 2003 pp. 19-20) shows that constant savings rate rules are inconsistent with the tax wedges shown Figure 1 and with the relation between consumption growth and lags of $r^{k}$. 
What would be the correlation if we could control for non-tax determinants of the business cycle? Consumption Euler equations may help produce an estimate of the supply elasticity of capital (see above), so that we could simulate the economic responses to capital taxation in the absence of a business cycle. But consumption Euler equations also suggest direct empirical estimates of capital income tax incidence, by emphasizing the tax-induced wedge between $r^{k}$ and consumption growth. Namely, consumption growth, raised to the appropriate power, is a variable that might capture other determinants of the business cycle. For example, to the extent that consumption growth was low during the Great Depression, the Euler equation attributes low pre-tax capital returns to the Depression, and not a lack of capital taxation as the raw correlation between $r^{k}$ and $\tau$ might suggest. So the empirical tax incidence question becomes: does capital taxation drive a wedge between consumption growth and pre-tax capital returns? Figure 1 suggests that capital taxation does drive a wedge, so that capital income taxes are passed on either immediately through higher prices charged by firms, or (to the extent that the marginal product of capital diminishes) eventually through reduced capital accumulation.

\section{References}

Alvarez, Fernando, and Urban J. Jermann. “Quantitative Asset Pricing Implications of Endogenous Solvency Constraints.” Review of Financial Studies. 14(4), Winter 2001: 1117-51.

Auerbach, Alan J. and Laurence J. Kotlikoff. Dynamic Fiscal Policy. Cambridge: Cambridge University Press, 1987.

Cagetti, Marco, Lars Peter Hansen, Thomas Sargent, and Noah Williams. "Robustness and Pricing with Uncertain Growth." Review of Financial Studies. 15(2), 2002: 363-404.

Feldstein, Martin. "The Effect of Marginal Tax Rates on Taxable Income: A Panel Study of the 1986 Tax Reform Act.” Journal of Political Economy. 103(3), June 1995: 551-72.

Feldstein, Martin S, Louis Dicks-Mireaux, and James Poterba. “The Effective Tax Rate and the Pretax Rate of Return.” Journal of Public Economics. 21(2), July 1983: 129-58.

Hall, Robert E. “Intertemporal Substitution in Consumption.” Journal of Political Economy. 96(2), April 1988: 339-57.

Hansen, Lars Peter and Kenneth J. Singleton. "Stochastic Consumption, Risk Aversion, and the Temporal Behavior of Asset Returns.” Journal of Political Economy. 91(2), April 1983: 
249-65.

Harrison, J. Michael and David M. Kreps. "Martingales and Arbitrage in Multiperiod Securities Markets." Journal of Economic Theory. 2(3), June 1979: 381-408.

Krzyzaniak, Marian, and Richard A. Musgrave. The Shifting of the Corporation Income Tax. Baltimore, MD: Johns Hopkins Press, 1963.

Mehra, Rajnish, and Edward C. Prescott. “The Equity Premium: A Puzzle.” Journal of Monetary Economics. 15(2), March 1985: 145-61.

Mulligan, Casey B. “Capital, Interest, and Aggregate Intertemporal Substitution.” NBER Working Paper \#9373, December 2002.

Mulligan, Casey B. “Capital Tax Incidence: Fisherian Impressions from the Time Series.” NBER Working Paper \#9916, August 2003.

Mulligan, Casey B. "Robust Aggregate Implications of Stochastic Discount Factor Volatility." NBER Working Paper \#10210, January 2004. 